\title{
Acoustic propagation modeling indicates vocal compensation in noise improves communication range for North Atlantic right whales
}

\author{
Jennifer B. Tennessen ${ }^{1,3, *}$, Susan E. Parks ${ }^{2}$ \\ ${ }^{1}$ Intercollege Graduate Degree Program in Ecology, and Department of Biology, The Pennsylvania State University, \\ 208 Mueller Laboratory, University Park, PA 16802, USA \\ ${ }^{2}$ Department of Biology, Syracuse University, 258 Life Sciences Complex, 107 College Place, Syracuse, NY 13244, USA \\ ${ }^{3}$ Present address: Department of Biology, Western Washington University, 516 High Street, M.S. 9160, Bellingham, \\ WA 98225, USA
}

\begin{abstract}
Sound from transoceanic shipping is a major component of ocean noise budgets. Baleen whale communication may be particularly vulnerable to shipping noise impacts due to overlap in the frequencies of signals and noise. Baleen whales rely upon acoustic signals to mediate a variety of social interactions when separated beyond visual range. We investigated the potential for noise to interfere with critical reunion events between mother-calf pairs of Endangered North Atlantic right whales Eubalaena glacialis, and whether vocal compensation can improve or maintain communication space between the sender and receiver. This information is necessary to inform future conservation efforts. We used acoustic propagation modeling to predict the transmission loss of the primary tonal communication signal used during mother-calf communication, the 'upcall', to (1) estimate over what ranges a receiving whale can detect a signal in anthropogenic noise, and (2) determine the effects of vocal compensation on detection range. Our results indicate that both point-source noise from nearby container ships and increased background noise from distant shipping may significantly limit communication space. Additionally, we show how amplitude and frequency compensation can increase the likelihood of detecting communication signals in masking noise under present conditions. We discuss these impacts of ship noise on communication, as well as the evidence that documented noise compensation behaviors of right whales can improve communication range in the presence of low-frequency ship noise.
\end{abstract}

KEY WORDS: Anthropogenic noise - Acoustic propagation modeling - Vocal compensation · Eubalaena glacialis $\cdot$ Mother-calf pair $\cdot$ Communication range

\section{INTRODUCTION}

Habitat loss is a leading driver of biodiversity loss (Millennium Ecosystem Assessment 2005). Over the past century, environmental noise from human activities has increased rapidly in intensity and scale, representing a drastic yet often overlooked form of habitat loss (Andrew et al. 2002, McDonald et al. 2006, Slabbekoorn \& Ripmeester 2008, Hildebrand 2009, Barber et al. 2010). This noise is primarily a consequence of human transportation, recreation,

\footnotetext{
${ }^{*}$ Corresponding author: jennifer.tennessen@gmail.com
}

and development (Slabbekoorn \& Ripmeester 2008, Hildebrand 2009, Barber et al. 2010), and transcends protected area boundaries (Barber et al. 2011). The loss of acoustic habitat, i.e. the components of the environment that enable an organism to effectively send and receive signals, impairs species' abilities to perceive sounds critical to survival, reproduction, population health and ecosystem integrity (e.g. Halfwerk et al. 2011, Francis et al. 2009, 2012, Tennessen et al. 2014; see reviews by Warren et al. 2006, Slabbekoorn \& Ripmeester 2008, Barber et al. 2010,

() The authors 2016. Open Access under Creative Commons by Attribution Licence. Use, distribution and reproduction are unrestricted. Authors and original publication must be credited. 
Kight \& Swaddle 2011). Consequently, the global increase in anthropogenic noise is an urgent conservation issue.

In some areas, underwater anthropogenic noise between 25 and $50 \mathrm{~Hz}$ increased by approximately $19 \mathrm{~dB}$ between 1950 and 2007, attributed to increases in commercial shipping (Frisk 2012). Due to limited light transmission in the marine environment, visual signaling is often restricted to a few meters. Consequently, marine mammals evolved to use sound for critical communication functions including navigating, foraging, and maintaining group cohesion (Au 1993, Tyack \& Miller 2002). The global increases in low-frequency ocean noise coincide with the main frequency range used by baleen whales to communicate acoustically and may impair successful communication by increasing the level at which a signal must be received in order to be heard above background noise (a phenomenon known as auditory masking; Payne \& Webb 1971, Richardson et al. 1995, Clark \& Ellison 2004, Nowacek et al. 2007, Weilgart 2007, Hatch et al. 2008). Auditory masking, a form of acoustic habitat loss, causes a reduction in the effective communication range between a sender and a receiver (Erbe 2002, Clark et al. 2009).

Reductions in communication range are likely problematic for cetaceans of all ages and sex classes, but are of particular concern for mothers with dependent young, for 2 reasons. First, as cetacean calves mature, they spend more time apart and at greater ranges from their mothers (Taber \& Thomas 1982, Szabo \& Duffus 2008, Cartwright \& Sullivan 2009, Gero et al. 2013). Thus, clear acoustic communication channels are critical to successfully maintain contact to allow for the pair to reunite, thereby increasing the probability that the calf will survive. However, despite the biological importance of communication between mothers and calves, we are aware of no studies that have explored how noise may impact communication between mother-calf pairs of baleen whales. Second, potential communication ranges between baleen whales are poorly understood (Clark et al. 2009). However, unlike communicating juveniles and/or adults, communication between mother and calf occurs between a defined sender and receiver whose separation distances can be realistically modeled. Thus, modeling how shipping noise may impact mother-calf communication space provides realistic scenarios with which to estimate loss of such space.

Considered one of the most urban whales and also one of the most endangered (Caswell et al. 1999,
Clapham et al. 1999, Kraus \& Rolland 2007), the North Atlantic right whale population consists of approximately 526 living, catalogued individuals (Pettis \& Hamilton 2015). Heavy shipping activity along the eastern coast of North America, dominated by transiting commercial vessels (Hatch \& Wright 2007, Hatch et al. 2008), overlaps the primary habitat of North Atlantic right whales (Hatch \& Wright 2007, Knowlton \& Brown 2007, Hatch et al. 2008). Given the high level of shipping activity, it is critical to understand the potential impacts of masking noise on right whale mother-calf acoustic communication. Indeed, anthropogenic noise may be contributing to the species' abnormally slow recovery from hunting during earlier centuries (Kraus \& Rolland 2007, Parks \& Clark 2007). The Bay of Fundy, Canada, one of the summer and fall foraging habitats for mothers with calves (Kraus et al. 2005), is dominated by some of the greatest, chronically elevated spectrum levels and band levels of noise that right whales encounter (Parks et al. 2009). For example, in 2004, ambient noise in the 50 to $350 \mathrm{~Hz}$ band was at least $105 \mathrm{~dB}$ re $1 \mu \mathrm{Pa} 96 \%$ of the time, compared to only $20 \%$ of the time off the coast of Georgia, USA (Parks et al. 2009). Calves spend the summer and early fall months in the sheltered, productive coastal waters of the North Atlantic Ocean, including the Bay of Fundy, as they near the weaning age of 8 to 17 mo (Hamilton et al. 1995). As weaning approaches, calves initiate the majority of reunions following separation events, whereas mothers initiate few (Taber \& Thomas 1982). During these separations, contact is maintained acoustically (Parks \& Clark 2007). Since much of the ambient anthropogenic noise in the Bay of Fundy overlaps the frequency range of right whale acoustic communication signals (Parks et al. 2007a, 2009), an increase in masking noise could reduce the communication range between mothers and calves. Since successful reproduction and rearing is fundamental to growing the population of Endangered North Atlantic right whales, understanding how noise impacts communication range provides insight into an anthropogenic impact that could limit right whale calf survival.

We used acoustic propagation modeling and assumptions about auditory masking in right whales to assess how ship noise impacts the communication space between mother-calf pairs of North Atlantic right whales in one of their critical habitats, the Bay of Fundy. Sound traveling through the ocean experiences distortion and loss in intensity through several processes including scattering, absorption, and 
attenuation (Urick 1983). Propagation modeling is a cost-effective, non-invasive approach to estimate the amount of absorption and attenuation a sound experiences along its path from sender to receiver (Urick 1983, Richardson et al. 1995, Etter 2013). Traditionally, applications of acoustic propagation modeling have been limited to marine seismology, military activities, and physical oceanography (e.g. Akal \& Berkson 1986, Clancy \& Johnson 1997, Caiti et al. 2000, Etter 2013). Recently, biological studies have utilized acoustic propagation modeling to quantify bioacoustic phenomena in ecological systems (MiksisOlds \& Miller 2006, Širović et al. 2007, Stafford et al. 2007, Clark et al. 2009, Samaran et al. 2010, Helble et al. 2013), demonstrating its utility for addressing questions at the interface of physics, ecology, and conservation.

We focused our study of mother-calf communication masking on the 'upcall,' one of the primary communication signals produced by mother-calf pairs of North Atlantic right whales (Parks \& Clark 2007, Parks et al. 2014). Upcalls are tonal sounds with an upsweep in frequency over the duration of the call, and are produced by both mothers and calves during separation events (Parks \& Clark 2007). Right whales increase the amplitude of their upcalls in noisy environments (Parks et al. 2011), and upcall frequency has increased over the past 50 yr (Parks et al. 2007a), suggesting that right whales employ vocal compensation to improve signal detection, a common strategy used by species across many taxa (e.g. Patricelli \& Blickley 2006, Nowacek et al. 2007, Hotchkin \& Parks 2013). However, the effectiveness of vocal compensation in improving communication space between right whales remains unknown.

To determine how anthropogenic noise from shipping activities impacts mother-calf communication space, and whether vocal compensation improves signal detection, we first modeled how point-source noise from a transiting container ship may affect the signal-to-noise ratio of upcalls received by a right whale at specified distances from the ship. Next, we tested the hypothesis that vocal compensation by right whales increases communication space in noise, and we explored whether documented changes in the amplitude and frequency of upcalls may be a behavioral response to compensate for noise, by modeling how these changes can increase the detection range of upcalls. Finally, we used published cumulative probability density functions of noise levels in the Bay of Fundy in 2005 to show how vocal compensation can increase the likelihood of detecting upcalls in noise.

\section{MATERIALS AND METHODS}

\section{Study site}

This study focuses on the potential effects of noise on right whale communication in one of the species' designated conservation areas, the Bay of Fundy (Brown et al. 1995). The Bay of Fundy is located off the southeastern coast of Canada, between New Brunswick and the Nova Scotia peninsula $\left(44.6667^{\circ} \mathrm{N}\right.$, $\left.66.5833^{\circ} \mathrm{W}\right)$. The bay is relatively shallow, generally less than $200 \mathrm{~m}$ deep, and the sediment floor is predominantly composed of varying combinations of coarse sand, clay, and silt (Curators of Marine and Lacustrine Geological Samples Consortium 2013). The bay is one of the only known summer foraging grounds for the North Atlantic right whale, and is therefore designated a conservation area in Canada (Brown et al. 1995). The bay is also a region that experiences substantial shipping activity, and contains a busy International Maritime Organizationdesignated shipping lane that crosses right whale critical habitat (Brown et al. 1995). Indeed, a comparison of noise among 3 important right whale habitat areas revealed the Bay of Fundy to have the greatest anthropogenic ambient noise levels (Parks et al. 2009).

\section{Transmission loss models}

Acoustic propagation modeling approximates a solution to the wave equation, a second-order partial differential equation that describes propagation of sound through an elastic medium (Urick 1983, Etter 2013). The wave equation, simplified to the time-independent Helmholz equation, relates pressure to location. Several techniques exist to estimate the solution to the wave equation, including normal mode, ray theory, multipath expansion, fast field, and parabolic equation (PE) approaches (Etter 2013). We used a PE approach (Hardin \& Tappert 1973) because it is range-dependent, allowing for exploration of transmission loss as a function of range; it performs well in shallow water; it is appropriate for lower frequencies typical of right whale vocalizations and ship noise (Richardson et al. 1995, Etter 2013); and it is among the most commonly used approaches for acoustic propagation modeling studies of marine mammal communication (Miksis-Olds \& Miller 2006, Stafford et al. 2007, Samaran et al. 2010, Helble et al. 2013).

Several computer models implement the PE approach. We used the Monterey-Miami Parabolic 


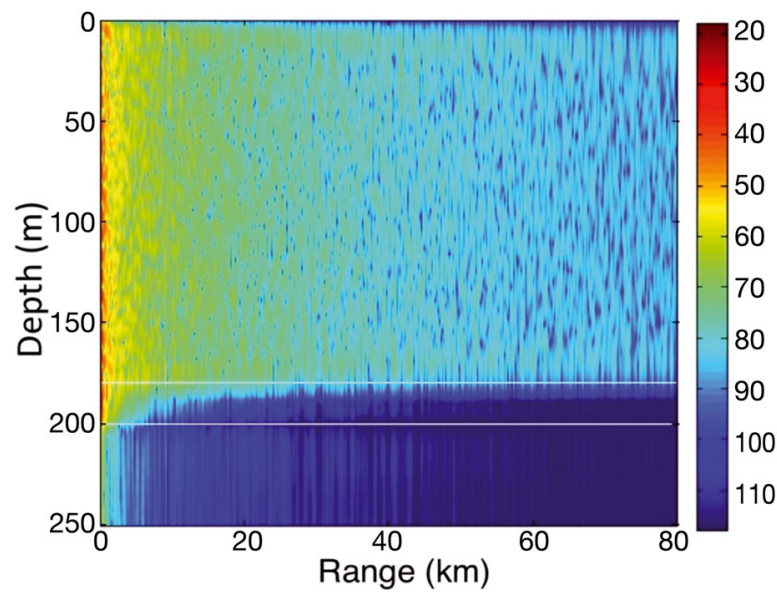

Fig. 1. Transmission loss plot for a North Atlantic right whale Eubalaena glacialis upcall (121 Hz, $5 \mathrm{~m}$ source depth). Color bar at right indicates loss in $\mathrm{dB}$ re $1 \mu \mathrm{Pa}$. Horizontal white lines indicate sea floor $(180 \mathrm{~m})$ and sub-sea floor $(200 \mathrm{~m})$

Equation model (MMPE, Smith 2001; downloaded from the US Office of Naval Research Ocean Acoustics Program Ocean Acoustics Library at http://oalib.hlsresearch.com/), a far-field approximation of horizontal acoustic propagation from a source. All acoustic propagation models have strengths and limitations in their applicability (Etter 2013). MMPE is one of the most common PE models (Hamm et al. 2016). It is well documented, efficient, accurate, and versatile (Smith 2001, Miksis-Olds \& Miller 2006). MMPE has been verified by empirical measurements (Miksis-Olds \& Miller 2006) and performs comparably to other propagation models under the conditions in which we were interested (Smith 2001). The MMPE model allows for parameterization of a sub-sea floor layer (e.g. sediment), enhancing real-world applicability. MMPE computes transmission loss as a function of range (Fig. 1), based on inputs of sound source properties, sound speed profile, and sea floor and sub-sea floor properties including range-dependent bathymetry. We defined these several habitat parameters, as follows.

\section{Source characteristics and receiver depth}

We determined the frequency, source level, and source depth for 2 signals, a transiting large container ship and an upcall, based on published literature (Table 1). To determine the appropriate bandwidth over which to calculate source levels of noise, we needed to specify right whale critical bands (the frequency range within which noise would mask the target frequency). While critical bands for baleen whales are unknown, evidence from terrestrial mammals as well as odontocetes and pinnipeds suggests that for low frequencies, the bandwidths of critical bands may be significantly greater than the 1/3octave band commonly assumed for mid-range frequencies (Fay 1988, Richardson et al. 1995). Additionally, noise at frequencies above or below the critical band can still mask the target frequency if the noise level is great enough (Kryter 1985). Therefore, we selected $50 \mathrm{~Hz}$ as a bandwidth of the critical band for the upcall (centered at $121 \mathrm{~Hz}$ ) and computed point-source and ambient noise source levels calculated over $50 \mathrm{~Hz}$ bandwidths, as:

$$
\mathrm{BL}_{50}=\mathrm{ISL}+10 \times \log _{10}(\Delta f)
$$

where $\mathrm{BL}_{50}=$ band level (intensity level over a $50 \mathrm{~Hz}$ band), ISL = intensity spectral level (intensity level in a $1 \mathrm{~Hz}$ band; obtained from data on container ship ISLs published in McKenna et al. 2012), and $\Delta f=$ change in frequency $(50 \mathrm{~Hz})$.

We are not aware of published values that report right whale upcall source level in ISLs. Therefore, we used the published upcall source level with a bandwidth of $9500 \mathrm{~Hz}$. To determine the potential error

Table 1. Sound source parameters used for detection range modeling. The bandwidth used to compute the only published data available for upcall source level was greater than the bandwidth we used to compute the container ship source level. However, based on comparisons of the error associated with using a wider bandwidth source level for the upcall, it is unlikely that this affected the qualitative trends of the results (see explanation in the 'Materials and methods')

\begin{tabular}{|lccccc|}
\hline Sound & $\begin{array}{c}\text { Depth } \\
(\mathrm{m})\end{array}$ & $\begin{array}{c}\text { Frequency } \\
(\mathrm{Hz})\end{array}$ & $\begin{array}{c}\text { Source level } \\
\left(\mathrm{dB}_{\mathrm{rms}} \mathrm{re} 1 \mu \mathrm{Pa} \text { at } 1 \mathrm{~m}\right)\end{array}$ & $\begin{array}{c}\text { Source level bandwidth } \\
(\mathrm{Hz})\end{array}$ & Reference \\
\hline Upcall & 5 & 121 & 150 & 9500 & $\begin{array}{l}\text { Parks \& Tyack (2005), } \\
\text { Parks et al. (2009, 2011) } \\
\text { Hatch et al. (2008), } \\
\text { Bassett et al. (2012), } \\
\text { McKenna et al. (2012) }\end{array}$ \\
\hline
\end{tabular}


associated with using a wider bandwidth source level for the upcall than the noise, we compared relative received levels over 2 bandwidths (approximately 7000 and $200 \mathrm{~Hz}$ ) of a subset of 18 right whale upcalls collected from acoustic recording tags attached to 4 right whales in the Bay of Fundy. The smaller bandwidth reduced relative received level by an average of $5.2 \%$, compared to the larger bandwidth. Therefore, while the wider bandwidth has a slightly greater relative received level, the majority of upcall energy is low-frequency $(<200 \mathrm{~Hz})$; thus we concluded that the published source level provided a reasonable value for our comparisons.

Since upcalls are commonly produced within a few meters of the ocean surface (Parks \& Tyack 2005, Parks et al. 2011), we used $5 \mathrm{~m}$ as the source depth. We assumed omni-directional transmission of these sounds, as others have done (Stafford et al. 2007, Clark et al. 2009, Samaran et al. 2010), which is reasonable for low-frequency sounds (Richardson et al. 1995). Receiver depth of right whales is variable. While right whales have been observed foraging at depths up to $175 \mathrm{~m}$ (Nowacek et al. 2001, Baumgartner \& Mate 2003), much of their foraging, social behavior, communication, and traveling occurs at or near the surface (Clark 1982, Parks \& Tyack 2005); therefore, we used $5 \mathrm{~m}$ as the receiver depth, representative of the depth at which the majority of communication is occurring. For this study, it was important to define only 1 depth each for sender and receiver. While outside the scope of this study, it would be interesting to explore how variation in sender and receiver depth impact communication masking.

\section{Sound speed profile}

We obtained conductivity, temperature, and depth (CTD) cast data from the Bay of Fundy for August and October, between 2000 and 2013, from the National Oceanographic Data Center (World Ocean Database 2013). We used no more than 1 CTD cast per day (to avoid overrepresentation and bias) to cre- ate monthly CTD averages, and used the procedure in Mackenzie (1981) to determine sound speed profile from the CTD casts. We compared modeled transmission loss of an upcall, using both the August and October sound speed profiles, to determine whether seasonal changes affected model results. Differences in the transmission loss of an upcall were negligible $(< \pm 0.5 \mathrm{~dB})$, so we used the August sound speed profile for this study.

Bathymetry and properties of sea floor and sub-sea floor

Bathymetry and sea floor composition in the Bay of Fundy were determined from the National Geophysical Data Center's Deck41 Surficial Sea Floor Sediment Description, which includes 25 samples from within the latitude and longitude range: 44.00 to $45.00^{\circ} \mathrm{N}, 66.00$ to $66.67^{\circ} \mathrm{W}$ (National Geophysical Data Center 2003) (Table 2). Sub-sea floor bathymetry and composition, as well as sea floor and sub-sea floor sediment properties, were determined from published literature (Todd \& Shaw 2011) (Table 2).

\section{Critical ratio of receiver}

While detection thresholds and critical ratios are available for smaller marine mammals such as some porpoises, dolphins, and pinnipeds, these auditory measurements are not available for right whales and other large baleen whales because their sizes preclude necessary hearing experiments (for selected recent advances in research on baleen whale hearing sensitivity, see Parks et al. 2007b, Yamato et al. 2012, Cranford \& Krysl 2015). We assumed a 0 dB critical ratio, following others (Širović et al. 2007), although a value greater than 0 may be more realistic (e.g. Southall et al. 2000, Stafford et al. 2007, Clark et al. 2009, Cunningham et al. 2014) and therefore our modeled detection ranges likely reflect the maximum possible communication space.

Table 2. Sea floor and sub-sea floor properties used for detection range modeling. Data from Hamilton (1971, 1980), and Todd \& Shaw (2011)

\begin{tabular}{|lccccccc|}
\hline Layer & $\begin{array}{c}\text { Depth } \\
(\mathrm{m})\end{array}$ & $\begin{array}{c}\text { Sound } \\
\text { speed } \\
\left(\mathrm{m} \mathrm{s}^{-1}\right)\end{array}$ & $\begin{array}{c}\text { Sound speed } \\
\text { gradient } \\
\left(1 \mathrm{~s}^{-1}\right)\end{array}$ & $\begin{array}{c}\text { Density } \\
\left(\mathrm{g} \mathrm{cm}^{-3}\right)\end{array}$ & $\begin{array}{c}\text { Compressional } \\
\text { attenuation } \\
\left(\mathrm{dB} \mathrm{m}^{-1} \mathrm{kHz}^{-1}\right)\end{array}$ & $\begin{array}{c}\text { Shear } \\
\text { speed } \\
\left(\mathrm{m} \mathrm{s}^{-1}\right)\end{array}$ & $\begin{array}{c}\text { Shear } \\
\text { attenuation } \\
\left(\mathrm{dB} \mathrm{m}^{-1} \mathrm{kHz}^{-1}\right)\end{array}$ \\
\hline Sea floor & 180 & 1836 & 0 & 2.03 & 0.079 & 250 & 1.60 \\
Sub-sea floor & 200 & 5300 & 0 & 2.70 & 0.004 & 2680 & 0.008 \\
\hline
\end{tabular}




\section{Estimates of upcall detection range in point-source noise}

Our general approach was to model the transmission loss (TL) of ship noise and overlay this with modeled transmission loss of a right whale upcall, to determine the acoustic field at a receiver at specified distances from the noise source. First, we used MMPE to estimate TL of ship noise in the Bay of Fundy, at $0.5,1,2,5,10$, and $25 \mathrm{~km}$ from the ship. For every range bin, MMPE computes a vector of TL values corresponding to each depth bin. Because we were only interested in TL of a signal between the surface and the depth of the receiver, we discarded all TL values below receiver depth, and averaged TL within the remaining depth bins, following an approach taken by others (Miksis-Olds \& Miller 2006, Stafford et al. 2007), to compress TL into 1 value per range bin, using a custom script in Matlab R2014a (The Mathworks). We then estimated the corresponding received levels of ship noise for a right whale at $0.5,1,2,5,10$, and $25 \mathrm{~km}$ from the ship as:

$$
\mathrm{RL}=\mathrm{SL}-\mathrm{TL}
$$

where $\mathrm{RL}=$ received level of signal at receiving whale (ship noise, in $\mathrm{dB}$ ), $\mathrm{SL}=$ source level of signal at $1 \mathrm{~m}$ from source (in $\mathrm{dB}$ ), and $\mathrm{TL}=$ transmission loss of signal along propagation path from source to receiver (in $\mathrm{dB}$ ).

Next, we used MMPE to estimate TL of an upcall as it propagates outward from a signaling right whale, and following the same approach for estimating ship noise RLs, we used Eq. (2) to obtain a vector of rangedependent upcall RLs. Finally, we solved for the range-dependent signal-to-noise ratio curves to estimate the maximum range over which an upcall would be detectable by a receiving right whale at $0.5,1,2,5,10$, and $25 \mathrm{~km}$ from a transiting ship as:

$$
\mathrm{SNR}=\mathrm{RL}-\mathrm{NL}
$$

where SNR = signal-to-noise ratio $($ in $\mathrm{dB}), \mathrm{RL}=$ received level of signal at receiving whale (upcall, in $\mathrm{dB}$ ), and $\mathrm{NL}=$ noise level (ship noise received by whale at specified distance from transiting ship; in dB).

\section{Vocal compensation}

We modeled 2 types of vocal compensation, viz. amplitude increase and frequency increase. To determine how increasing amplitude alters communication space, we defined 2 levels of amplitude compensation for an upcall (10 and $20 \mathrm{~dB}$ ), based on published data on modifications of communication signal levels across many species, including right whales (e.g. Holt et al. 2009, Parks et al. 2011, reviewed in Hotchkin \& Parks 2013). We added the amplitude compensation level to the upcall source level, solved for the rangedependent upcall received levels, and then solved for the range-dependent SNR curves (as above), to estimate maximum detection ranges.

To determine how an increase in frequency alters communication space, we used MMPE to estimate the range-dependent TL of upcalls from 2 different periods - those from 1956 and 2000-2004 (70 Hz and $101 \mathrm{~Hz}$ mean start frequencies, respectively; Parks et al. 2007a). We obtained a vector of range-dependent received levels (Eq. 2), determined band level ambient noise (Eq. 1, $50 \mathrm{~Hz}$ bandwidth, ISL $=85 \mathrm{~dB}$ re $1 \mu \mathrm{Pa}^{2} \mathrm{~Hz}^{-1}$ based on Bay of Fundy noise measurements; Parks et al. 2009), and estimated SNR in band level ambient noise (Eq. 3), to compare detection ranges of historic and modern upcalls in present ambient noise conditions.

\section{Estimates of cumulative probability density functions for detection ranges}

We used published data from Parks et al. (2009) that defined the cumulative probability density function (CPDF) of ambient noise in the Bay of Fundy during 2005, based on recordings made from bottommounted passive acoustic recording units. These data define the percent of time ambient noise in the band between 50 and $350 \mathrm{~Hz}$ was below a specified intensity level. Therefore, we used the following equation to adjust the $300 \mathrm{~Hz}$ bandwidth CPDF band levels to ISL, and then used Eq. (1) to compute corresponding $50 \mathrm{~Hz}$ bandwidth CPDF band levels of ambient noise:

$$
\mathrm{ISL}=\mathrm{BL}_{\text {total }}-10 \times \log _{10}(\Delta f)
$$

where ISL = intensity level in a $1 \mathrm{~Hz}$ band, $\mathrm{BL}_{\text {total }}=$ band level (intensity level over the frequency range between 50 and $350 \mathrm{~Hz}$ ), and $\Delta f=$ change in frequency $(300 \mathrm{~Hz})$.

We determined the CPDF for the upcall detection range (the likelihood that the maximum detection range was less than or equal to a given distance from the signaler) using the adjusted CPDF band levels of ambient noise. Assuming a receiver critical ratio equal to $0 \mathrm{~dB}$, the maximum detection range is the distance at which the received level of a communication signal equals the ambient noise level in the critical band. Therefore, we set the critical ratio equal to 
0 , determined the vector of upcall TL values that correspond with the vector of adjusted CPDF ambient noise levels (Eq. 5), and computed the vector of distances corresponding with the vector of upcall TL values. Using this approach, we computed CPDF curves for the detection ranges of 2 upcalls (1956 and 2000) under 3 compensation scenarios $(0,10$, and $20 \mathrm{~dB})$.

$$
\mathrm{CR}+\mathrm{NL}=\mathrm{SL}-\mathrm{TL}
$$

where $\mathrm{CR}=$ critical ratio $($ in $\mathrm{dB}), \mathrm{NL}=$ ambient noise level (in dB), SL = source level of upcall at $1 \mathrm{~m}$ from signaling whale (in $\mathrm{dB}$ ), $\mathrm{TL}=$ transmission loss of upcall along propagation path from signaler to receiver (in dB).

\section{RESULTS}

\section{Upcall detection range in point-source noise}

Our model demonstrated that point-source noise from a container ship transiting past a receiving whale may substantially reduce the SNR of upcalls and, consequently, the upcall detection range. With a critical ratio estimate of $0 \mathrm{~dB}$, an upcall would only be detected in the scenario in which the receiving whale is $25 \mathrm{~km}$ from the transiting ship, and only when the receiving whale is no more than $320 \mathrm{~m}$ from the signaling whale (see Table 3). For a more conservative critical ratio estimate of $5 \mathrm{~dB}$, the results suggest that upcalls would not be detectable by a receiver in any of the noise scenarios, at any distance from the signaling whale (Fig. 2).

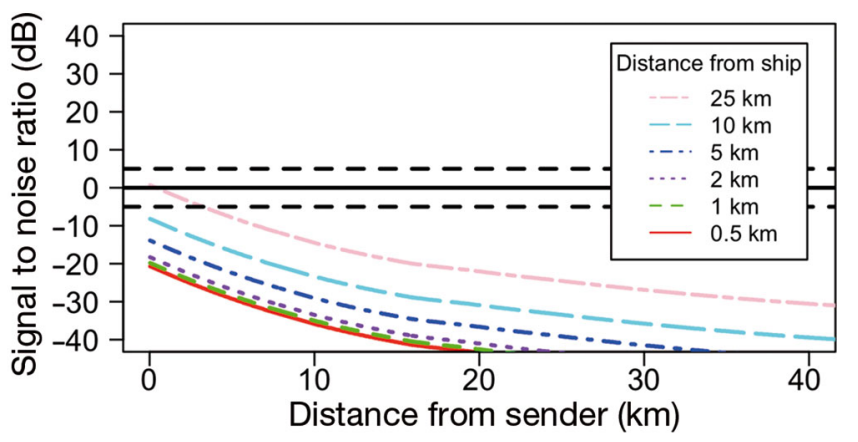

Fig. 2. Detection ranges of the North Atlantic right whale Eubalaena glacialis upcall by a receiver at $0.5,1,2,5,10$, and $25 \mathrm{~km}$ from point-source noise produced by a container ship. Horizontal black lines correspond to receiver critical ratios of $0 \mathrm{~dB}$ (solid) and $\pm 5 \mathrm{~dB}$ (dashed). For a critical ratio of $0 \mathrm{~dB}$, detection of an upcall would only occur at $25 \mathrm{~km}$ from a container ship. For a critical ratio of $5 \mathrm{~dB}$, signal detection would fail in all scenarios modeled, at all distances from a signaling whale

\section{Vocal compensation}

Increasing the upcall amplitude increases detection range. Only for the scenario in which the receiving whale is $25 \mathrm{~km}$ from the transiting ship do our results suggest it could detect an upcall if the signaling whale does not employ amplitude compensation. Increasing the upcall source level by $10 \mathrm{~dB}$, however, would enable the upcall to be detected over a short range when a container ship is 10 and $25 \mathrm{~km}$ away. The $20 \mathrm{~dB}$ amplitude compensation further increases the radius of the receiving whale's detection range for scenarios with a container ship 10 and $25 \mathrm{~km}$ away, and additionally enables short-range detection by a receiver 1,2 , and $5 \mathrm{~km}$ from a container ship (Table 3, Fig. 3).

Increasing the upcall start frequency also increases detection range. The modern upcall (2000: $101 \mathrm{~Hz}$ start frequency) experiences less transmission loss than the historic upcall (1956: $70 \mathrm{~Hz}$ start frequency) (Fig. 4a). Consequently, the detection range of the modern upcall is greater than the detection range of the historic upcall by a receiver in present day ambient noise levels in the Bay of Fundy. Furthermore, amplitude and frequency compensation in tandem produce the greatest detection range of an upcall (Fig. 4b).

\section{Cumulative probability density functions for detection ranges in the Bay of Fundy}

Our results suggest that the detection range of the 2000 upcall is greater than that of the 1956 upcall in 2005 Bay of Fundy ambient noise. Additionally, amplitude compensation increases the likelihood of upcall detection. For example, the detection range of a 1956 upcall with a $10 \mathrm{~dB}$ increase in amplitude was less than $3 \mathrm{~km}$ approximately $100 \%$ of the time, whereas the detection range of a 2000 upcall with a $10 \mathrm{~dB}$ increase in amplitude was less than $3 \mathrm{~km}$ approximately $90 \%$ of the time, and the detection range for a 2000 upcall with a $20 \mathrm{~dB}$ increase in amplitude was less than $3 \mathrm{~km}$ approximately $30 \%$ of the time (Fig. 5).

\section{DISCUSSION}

In this investigation, we used acoustic propagation modeling to predict how underwater anthropogenic noise may impair the communication range between mother-calf pairs of Endangered North Atlantic right 


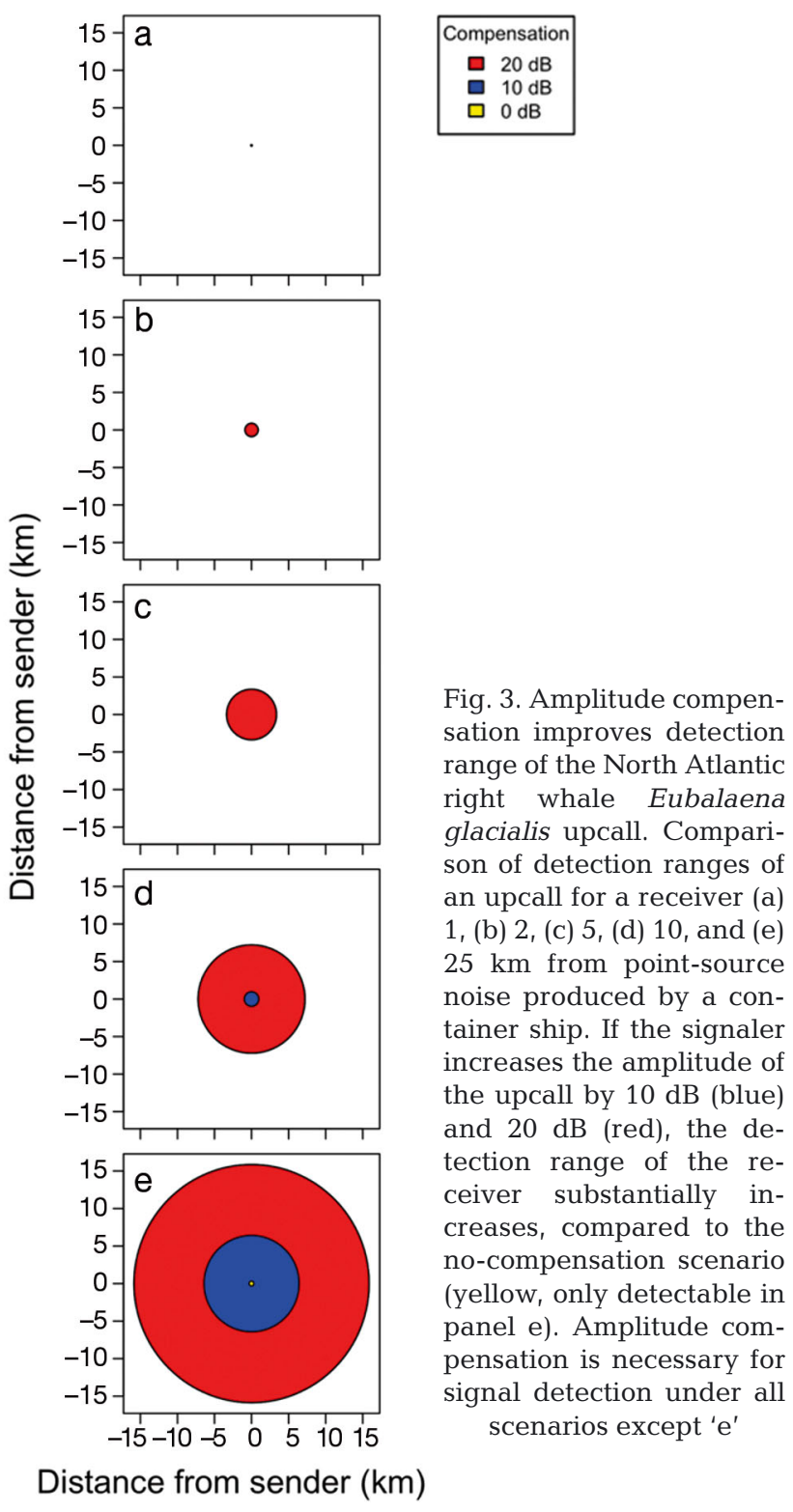

Table 3. Maximum detection ranges of an upcall by a receiving whale near a transiting container ship, with and without amplitude compensation. If a signaling whale increases the amplitude of its upcall by 10 or $20 \mathrm{~dB}$, the detection range for the receiving whale increases. Distance: distance between receiver and ship

\begin{tabular}{|lccc|}
\hline \multirow{2}{*}{$\begin{array}{l}\text { Distance } \\
(\mathrm{km})\end{array}$} & \multicolumn{3}{c|}{ Maximum detection range $(\mathrm{km})$} \\
\cline { 2 - 4 } & No compensation & 10 dB increase & 20 dB increase \\
\hline 0.5 & 0 & 0 & 0 \\
1 & 0 & 0 & 0.08 \\
2 & 0 & 0 & 0.88 \\
5 & 0 & 0.96 & 3.36 \\
10 & 0 & 6.41 & 7.21 \\
25 & 0.32 & & 15.86 \\
\hline
\end{tabular}
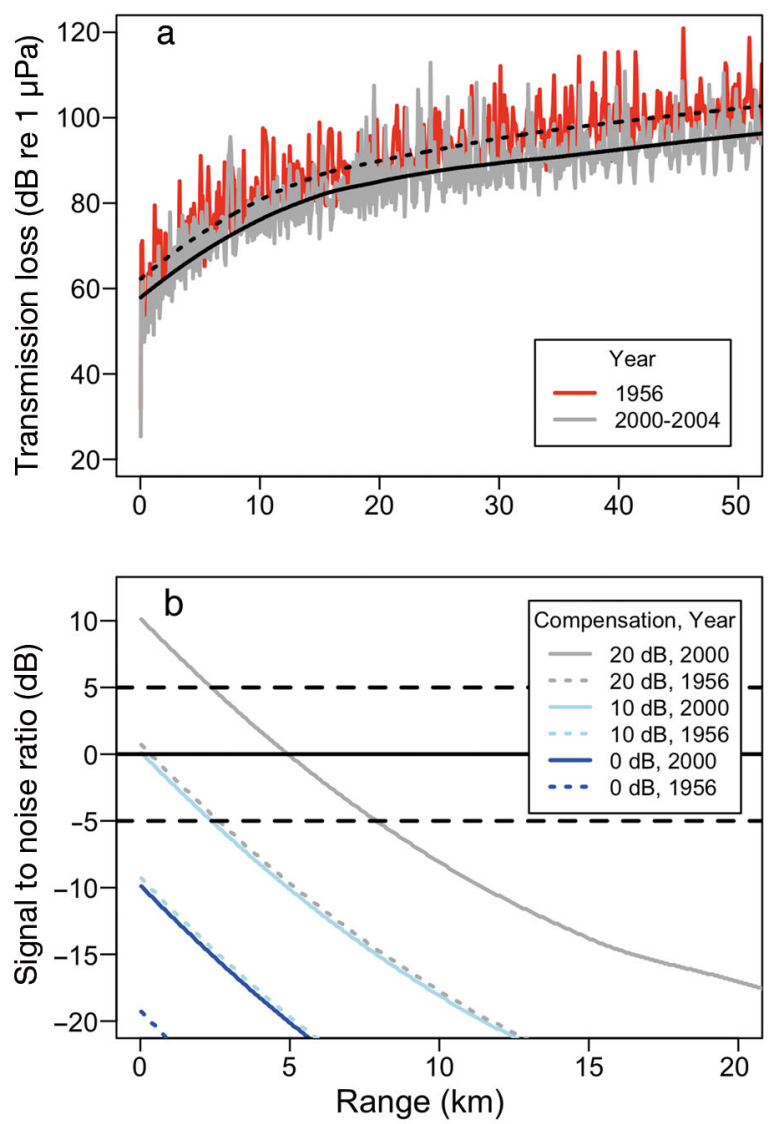

Fig. 4. Frequency compensation improves detection range of the North Atlantic right whale Eubalaena glacialis upcall. (a) Transmission loss of upcalls from 1956 (red, $70 \mathrm{~Hz}$ mean start frequency) and 2000 (gray, $101 \mathrm{~Hz}$ mean start frequency). Smoothed curves for the 1956 (dashed) and 2000 (solid) upcalls indicate that the increase in mean start frequency, which occurred over at most $50 \mathrm{yr}$ in the North Atlantic right whale population, corresponds with a reduction in upcall transmission loss. (b) Combining frequency and amplitude compensation enables the greatest upcall detection range in present-day ambient noise. Model results suggest the 2000 upcall (solid lines) is better suited than the 1956 upcall (dotted lines) to the average ambient ocean soundscape in the Bay of Fundy $(50 \mathrm{~Hz}$ bandwidths of ambient noise, centered at 101 and $70 \mathrm{~Hz}$, respectively: 102 vs $107 \mathrm{~dB}$ re $1 \mu \mathrm{Pa}$ ). Horizontal solid and dashed black lines illustrate 0 and $\pm 5 \mathrm{~dB}$ critical ratios, respectively

whales, and to illustrate how vocal compensation strategies commonly employed by marine mammals can improve the range over which communication signals can be detected. We found that point-source noise from a transiting container ship substantially limits upcall detection range, similar to models of communication range on Stellwagen Bank (Clark et al. 2009). Increasing upcall amplitude and frequency, however, greatly increases upcall detection range during point-source noise. Indeed, model results suggest that the documented $30 \mathrm{~Hz}$ increase in average 


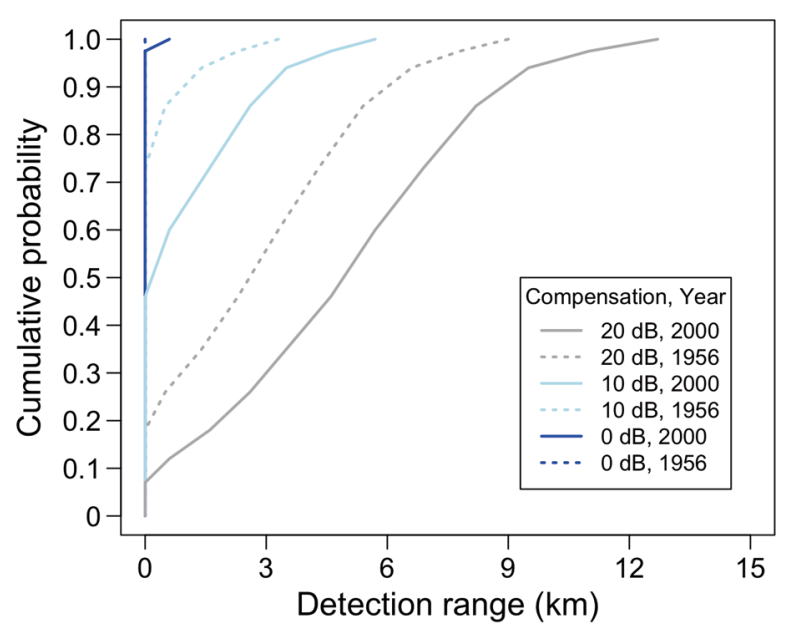

Fig. 5. Cumulative probability of the maximum detection range of the North Atlantic right whale Eubalaena glacialis upcall in the Bay of Fundy, based on 2005 ambient noise recordings reported by Parks et al. (2009). These curves illustrate the likelihood that detection range is less than or equal to a given range (to the left of each line), for upcalls from 1956 (dotted; $70 \mathrm{~Hz}$ start frequency) and 2000 (solid; $101 \mathrm{~Hz}$ start frequency) in 3 amplitude compensation scenarios: $0 \mathrm{~dB}$ (dark blue), $10 \mathrm{~dB}$ increase (light blue), and $20 \mathrm{~dB}$ increase (gray). Note that the ' $0 \mathrm{~dB}, 1956$ ' line indicates a 1.0 probability of the detection range being $0 \mathrm{~km}$

upcall minimum frequency that occurred during the last half of the 20th century, and coincided with increases in low-frequency ambient noise, reduced upcall transmission loss and increased detection range. Finally, based on published values of noise levels in the Bay of Fundy in 2005, we show how amplitude and frequency compensation, in tandem, can increase the likelihood of communication signal detection by a receiving whale in masking noise.

For this study we used the MMPE model from the PE class of models. When used correctly, high-fidelity models including MMPE can accurately compute sound fields (Hamm et al. 2016). MMPE is one of the most common PE models (Etter 2013, Hamm et al. 2016). A study on transmission loss of manatee acoustic signals showed reasonable agreement between MMPE-modeled data and empirical measurements (Miksis-Olds \& Miller 2006). However, empirical measurements for transmission loss of baleen whale communication signals are logistically impractical. Instead, baleen whale studies using acoustic propagation modeling to estimate detection ranges have typically selected one most appropriate highfidelity model for their purposes (e.g. Širović et al. 2007, Stafford et al. 2007, Samaran et al. 2010, Helble et al. 2013). We have taken a similar approach. Thus, our results are specific to MMPE. Future research that quantifies how model selection affects cetacean communication detection range estimates would contribute significantly to this field.

In this study, we specifically focused on the Bay of Fundy because of its dual status as an area with substantial shipping activity and as a critical habitat for right whales, especially mother-calf pairs that spend increasing time apart and communicate over distance. While our results are specific to the Bay of Fundy, our approach to examine communication masking and vocal compensation would be useful in other important right whale habitats that receive shipping noise, especially since distribution patterns of mother-calf pairs and other age/sex classes of right whales have shifted in recent years (Pettis \& Hamilton 2015).

Our findings are dependent on the availability of data to parameterize our models. Thus, it is important to note 5 factors in our selection of model parameters. First, to compute CPDFs for upcall detection, we relied on published data on ambient noise in the Bay of Fundy collected using bottom-mounted recording units. Since radiated ship noise loses energy along its propagation path, the received noise levels at the bottom-mounted units may be lower than surface levels where most communication is occurring. Thus, our CPDFs likely represent best-case scenarios for upcall detection ranges. Second, in the absence of data on baleen whale hearing abilities, we assumed a critical ratio of $0 \mathrm{~dB}$, and considered the effects of $\pm 5 \mathrm{~dB}$ critical ratios where relevant. It is possible that even a $5 \mathrm{~dB}$ critical ratio is an underestimate. Critical ratios and critical bands across mammalian taxa, including odontocetes and pinnipeds, show consistent trends (Fay 1988, Southall et al. 2000). Therefore, it is reasonable to apply knowledge gained from studies of pinniped critical ratios to formulate predictions about baleen whale critical ratios. Southall et al. (2000) found that critical ratios for detecting a $100 \mathrm{~Hz}$ signal by a northern elephant seal Mirounga angustirostris and a harbor seal Phoca vitulina were 14 and $16 \mathrm{~dB}$, respectively. Therefore, a $15 \mathrm{~dB}$ critical ratio for a right whale upcall centered at $121 \mathrm{~Hz}$ may be reasonable. A $15 \mathrm{~dB}$ critical ratio would significantly reduce our estimated detection range for an individual $25 \mathrm{~km}$ from a transiting ship by approximately $80 \%$ to $3.12 \mathrm{~km}$ under the $20 \mathrm{~dB}$ amplitude compensation scenario. Detection range would be $0 \mathrm{~km}$ for all other scenarios and ranges modeled. Furthermore, mammals are generally better at detecting signals than at discriminating between or recognizing certain features within multiple signals (Clark et al. 2009). Thus, our estimates of detection range, based on the best available data, may over- 
estimate upcall communication range, and may be considered best-case scenarios. Third, we limited our investigation to upcall start and peak frequencies. It is possible that other aspects of the signal, such as maximum frequency, are important for communication and would impact the values calculated in this study. However, the qualitative trends in relative detection ranges would remain the same, whether or not we modified the critical ratios or frequency ranges tested. Future studies that determine hearing capabilities in baleen whales will contribute substantially to determining how noise impacts communication space. Fourth, it is possible that right whales may change the kinds of signals produced in noise. Indeed, humpback whales Megaptera novaeangliae switched from mostly vocal signals to mostly surfacegenerated signals during increased wind speeds and ambient noise levels (Dunlop et al. 2010). Whether right whales similarly incorporate more percussive behaviors into their acoustic displays during periods of greater ambient noise is unknown. While surfacegenerated behaviors such as breaches and fluke slaps are broadband and have high source levels, they likely contain less information (Dunlop et al. 2010). Therefore, such communication modification may not necessarily be an effective strategy for enhancing signal detection. Finally, all modeling has tradeoffs in representing real world complexity. In particular, we chose to model the low-frequency ship noise that is primarily due to propeller cavitation (Urick 1983, Richardson et al. 1995) as point-source noise, an approach used in earlier studies (Ross 1976, Urick 1983). While this approach is reasonable for representing noise propagating over a distance from the source (but see Wales \& Heitmeyer 2002), models that incorporate more complex ship noise radiation patterns may also be valuable.

Our findings suggest that, unlike the communication signals of some other large baleen whales, right whale upcalls are not long-distance communication signals. Rather, our results suggest that these signals achieve maximum detection ranges less than $16 \mathrm{~km}$ when vocal compensation is accounted for, in the 'quietest' noise scenario modeled (Fig. 3e, Table 3). Species such as the blue whale Balaenoptera musculus and fin whale $B$. physalus call at lower frequencies and in deeper habitats in which these lowfrequency signals may propagate efficiently over hundreds of kilometers (Bass \& Clark 2003). In contrast, right whale communication signals are produced primarily in shallow environments in which transmission loss is a main limiting factor on communication range of low-frequency signals (Bass \&
Clark 2003). The peak frequency range of upcalls coincides with a frequency range (approximately $100-300 \mathrm{~Hz}$ ) in which there was historically minimal ambient noise present (Clark 1982, Clark \& Ellison 2004). Selection on upcall frequency may have favored this acoustic window in which ambient noise was low (Clark et al. 2007), thereby maximizing efficient propagation over relatively short distances in shallow water, and potentially acoustically shielding calves from predators. However, due to efficient propagation of ship noise in the upcall frequency range (Clark et al. 2007), right whale communication is mismatched to present-day acoustic environments dominated by masking noise.

Our findings shed light on the potential effectiveness of species-specific responses to increasing noise levels in the ocean. North Atlantic right whales call louder in anthropogenic noise (Parks et al. 2009). This noise compensation strategy, observed across many taxa, is a technique for improving detection of acoustic signals (reviewed by Hotchkin \& Parks 2013). Often, however, the amount of amplitude increase depends on the noise level (e.g. Holt et al. 2009, 2011, Parks et al. 2011). This makes sense from a conservation of energy perspective, as calling louder may have energetic and metabolic costs (Oberweger \& Goller 2001, Noren et al. 2013). The amount of amplitude increase is presumably limited by some physiological threshold (Parks et al. 2011). Therefore, while our findings show that amplitude compensation is an effective way to improve the detection range of signals, this response may not be a sustainable solution if ocean noise levels continue to rise. Alternatively, improvements in noise containment technology would substantially increase detection ranges of right whale communication signals by reducing noise levels. Implicit in our simulations are parameters defining peak frequency and amplitude of ship noise. Technology that lowered noise amplitude would result in increased right whale mothercalf communication space and improved detection ranges for passive monitoring efforts.

We show that increasing the frequency of upcalls also improves communication range. This result is consistent with predictions from signal detection theory and with studies documenting frequency increases in noise by many species (reviewed in Patricelli \& Blickley 2006). In right whales, upcall start frequency increased by an average of approximately $30 \mathrm{~Hz}$ over the second half of the last century (Parks et al. 2007a), a period in which low-frequency ocean noise levels steadily increased (Andrew et al. 2002, McDonald et al. 2006, Frisk 2012). Our results show 
that, due to shallow water effects, the higher-frequency, modern upcall achieves less transmission loss, and therefore has a greater signal-to-noise ratio in present-day ambient noise in the Bay of Fundy, compared with the 1956 upcall. These results suggest that the documented increase in upcall frequency may be an adaptive response by right whales to globally increasing levels of ocean noise. Furthermore, since right whales are long-lived, these changes occurred within the lifetimes of many of the individuals in the population. Future studies that determine the extent to which right whales and other long-lived species may be able to respond within their lifetimes to rapid environmental change will contribute significantly to understanding species' resilience in the face of a changing planet.

Acknowledgements. We thank T. Langkilde, T. Tennessen, T. Gabrielson, E. Post, M. Sheriff, D. Cusano, S. Denes, C. Hotchkin, M. Brown, A. Knowlton, M. Zani, L. Conger, and S. Kraus for valuable feedback. We are grateful for logistical assistance and field support provided by the New England Aquarium. This work was supported by The Pennsylvania State University (Academic Computing Fellowship to J.B.T., and the Applied Research Laboratory) and the Office of Naval Research (Award no. N00014-12-1-0268).

\section{LITERATURE CITED}

Akal T, Berkson JM (eds) (1986) Ocean seismo-acoustics: low-frequency underwater acoustics. NATO Conference Series IV, Marine Sciences 16. Plenum, New York, NY

Andrew RK, Howe BM, Mercer JA, Dzieciuch MA (2002) Ocean ambient sound: comparing the 1960s with the 1990s for a receiver off the California coast. Acoust Res Lett Online 3:65-70

$\mathrm{Au}$ WWL (1993) The sonar of dolphins. Springer-Verlag, New York, NY

> Barber JR, Crooks CR, Fristrup KM (2010) The costs of chronic noise exposure for terrestrial organisms. Trends Ecol Evol 25:180-189

Barber JR, Burdett CL, Reed SE, Warner KA and others (2011) Anthropogenic noise exposure in protected natural areas: estimating the scale of ecological consequences. Landsc Ecol 26:1281-1295

Bass AH, Clark CW (2003) The physical acoustics of underwater sound communication. In: Simmons A, Popper AN, Fay R (eds) Acoustic communication. Springer, New York, NY, p 15-64

Bassett C, Polagye B, Holt M, Thompson J (2012) A vessel noise budget for Admiralty Inlet, Puget Sound, Washington (USA). J Acoust Soc Am 132:3706-3719

Baumgartner MF, Mate BR (2003) Summertime foraging ecology of North Atlantic right whales. Mar Ecol Prog Ser 264:123-135

Brown MW, Allen JM, Kraus SD (1995) The designation of seasonal right whale conservation areas in the waters of Atlantic Canada. In: Shackell NL, Willison JHM (eds) Marine protected areas and sustainable fisheries.
Science and Management of Marine Protected Areas Association, Wolfville, NS, p 90-98

Caiti A, Hermand JP, Jesus S, Porter M (eds) (2000) Experimental acoustic inversion methods for exploration of the shallow water environment. Kluwer Academic Publishers, Dordrecht

> Cartwright R, Sullivan M (2009) Behavioral ontogeny in humpback whale (Megaptera novaeangliae) calves during their residence in Hawaiian waters. Mar Mamm Sci 25:659-680

Caswell H, Fujiwara M, Brault S (1999) Declining survival probability threatens the North Atlantic right whale. Proc Natl Acad Sci USA 96:3308-3313

Clancy RMA, Johnson A (1997) An overview of naval operational ocean modeling. Mar Technol Soc J 31:54-62

Clapham PJ, Young SB, Brownell RL Jr (1999) Baleen whales: conservation issues and the status of the most endangered populations. Mammal Rev 29:37-62

Clark CW (1982) The acoustic repertoire of the southern right whale, a quantitative analysis. Anim Behav 30: 1060-1071

Clark CW, Ellison WT (2004) Potential use of low-frequency sounds by baleen whales for probing the environment: evidence from models and empirical measurements. In: Thomas J, Moss C, Vater M (eds) Advances in the study of echolocation in bats and dolphins. University of Chicago Press, Chicago, IL, p 564-582

Clark CW, Gillespie D, Nowacek DP, Parks SE (2007) Listening to their world: acoustics for monitoring and protecting right whales in an urbanized ocean. In: Kraus SD, Rolland RM (eds) The urban whale: North Atlantic right whales at the crossroads. Harvard University Press, Cambridge, MA, p 333-357

Clark CW, Ellison WT, Southall BL, Hatch L, Van Parijs SM, Frankel A, Ponirakis D (2009) Acoustic masking in marine ecosystems: intuitions, analysis, and implication. Mar Ecol Prog Ser 395:201-222

> Cranford TW, Krysl P (2015) Fin whale sound reception mechanisms: skull vibration enables low-frequency hearing. PLoS One 10:e0116222

- Cunningham KA, Southall BL, Reichmuth C (2014) Auditory sensitivity of seals and sea lions in complex listening scenarios. J Acoust Soc Am 136:3410-3421

Curators of Marine and Lacustrine Geological Samples Consortium (2013) The Index to Marine and Lacustrine Geological Samples (IMLGS). National Geophysical Data Center, NOAA National Centers for Environmental Information, https://www.ngdc.noaa.gov/mgg/curator/

Dunlop RA, Cato DH, Noad MJ (2010) Your attention please: increasing ambient noise levels elicits a change in communication behaviour in humpback whales (Megaptera novaeangliae). Proc R Soc Lond B Biol Sci 277:2521-2529

> Erbe C (2002) Underwater noise of whale-watching boats and potential effects on killer whales (Orcinus orca), based on an acoustic impact model. Mar Mamm Sci 18: 394-418

Etter PC (2013) Underwater acoustic modeling and simulation, $4^{\text {th }}$ edn. CRC Press, Boca Raton, FL

Fay RR (1988) Hearing in vertebrates: a psychophysics databook. Hill-Fay Associates, Winnetka, IL

- Francis CD, Ortega CP, Cruz A (2009) Noise pollution changes avian communities and species interactions. Curr Biol 19:1415-1419

Francis CD, Kleist NJ, Ortega CP, Cruz A (2012) Noise pollution alters ecological services: enhanced pollination 
and disrupted seed dispersal. Proc R Soc Lond B Biol Sci 279:2727-2735

Frisk GV (2012) Noiseonomics: the relationship between ambient noise levels in the sea and global economic trends. Sci Rep 2:437

Gero S, Gordon J, Whitehead H (2013) Calves as social hubs: dynamics of the social network within sperm whale units. Proc R Soc Lond B Biol Sci 280:20131113

Halfwerk W, Holleman LJM, Lessels CM, Slabbekoorn H (2011) Negative impact of traffic noise on avian reproductive success. J Appl Ecol 48:210-219

Hamilton EL (1971) Prediction of in-situ acoustic and elastic properties of marine sediments. Geophysics 36:266-284

Hamilton EL (1980) Geoacoustic modeling of the sea floor. J Acoust Soc Am 68:1313-1340

Hamilton PK, Marx MK, Kraus SD (1995) Weaning in North Atlantic right whales. Mar Mamm Sci 11:386-390

Hamm CA, McCammon DF, Taillefer ML (2016) Underwater sound propagation modeling methods for predicting marine animal exposure. In: Popper AN, Hawkins A (eds) The effects of noise on aquatic life II. Vol 875, Advances in Experimental Medicine and Biology, Springer, New York, NY, p 381-389

Hardin RH, Tappert FD (1973) Applications of the split-step Fourier method to the numerical solution of nonlinear and variable coefficient wave equations. SIAM Rev 15: 423-429

Hatch LT, Wright AJ (2007) A brief review of anthropogenic sound in the oceans. Int J Comp Psychol 20:121-133

Hatch L, Clark C, Merrick R, Van Parijs S and others (2008) Characterizing the relative contributions of large vessels to total ocean noise fields: a case study using the Gerry E. Studds Stellwagen Bank National Marine Sanctuary. Environ Manag 42:735-752

Helble TA, Gerald LD, Hildebrand JA, Campbell GS, Campbell RL, Heaney KD (2013) Site specific probability of passive acoustic detection of humpback whale calls from single fixed hydrophones. J Acoust Soc Am 134: $2556-2570$

Hildebrand J (2009) Anthropogenic and natural sources of ambient noise in the ocean. Mar Ecol Prog Ser 395:5-20

Holt MM, Noren DP, Veirs V, Emmons CK, Veirs S (2009) Speaking up: killer whales (Orcinus orca) increase their call amplitude in response to vessel noise. J Acoust Soc Am 125:EL27-EL32

> Holt MM, Noren DP, Emmons CK (2011) Effects of noise levels and call types on the source levels of killer whale calls. J Acoust Soc Am 130:3100-3106

Hotchkin C, Parks S (2013) The Lombard effect and other noise-induced vocal modifications: insight from mammalian communication systems. Biol Rev Camb Philos Soc 88:809-824

Kight CR, Swaddle JP (2011) How and why environmental noise impacts animals: an integrative, mechanistic review. Ecol Lett 14:1052-1061

Knowlton AR, Brown MW (2007) Running the gauntlet: right whales and vessel strikes. In: Kraus SD, Rolland RM (eds) The urban whale: North Atlantic right whales at the crossroads. Harvard University Press, Cambridge, MA, p 409-435

Kraus SD, Rolland RM (2007) Right whales in the urban ocean. In: Kraus SD, Rolland RM (eds) The urban whale: North Atlantic right whales at the crossroads. Harvard University Press, Cambridge, MA, p 1-38

Kraus SD, Brown MW, Caswell H, Clark CW and others
(2005) North Atlantic right whales in crisis. Science 309: 561-562

Kryter KD (1985) The effects of noise on man, $2^{\text {nd }}$ edn. Academic Press, Orlando, FL

> Mackenzie KV (1981) Nine-term equation for sound speed in the oceans. J Acoust Soc Am 70:807-812

> McDonald MA, Hildebrand JA, Wiggins SM (2006) Increases in deep ocean ambient noise in the Northeast Pacific west of San Nicolas Island. J Acoust Soc Am 120: 711-718

McKenna MF, Ross D, Wiggins SM, Hildebrand JA (2012) Underwater radiated noise from modern commercial ships. J Acoust Soc Am 131:92-103

Miksis-Olds JL, Miller JH (2006) Transmission loss in manatee habitats. J Acoust Soc Am 120:2320-2327

Millennium Ecosystem Assessment (2005) Ecosystems and human well-being: biodiversity synthesis. World Resources Institute, Washington, DC

National Geophysical Data Center (2003) Seafloor surficial sediment descriptions, Deck41, Data Set G02094. National Oceanic and Atmospheric Administration. https://data.noaa.gov/dataset/deck41-surficial-seafloorsediment-description-database (accessed 19 November 2013)

Noren DP, Holt MM, Dunkin RC, Williams TM (2013) The metabolic cost of communicative sound production in bottlenose dolphins (Tursiops truncatus). J Exp Biol 216: 1624-1629

Nowacek DP, Johnson MP, Tyack PL, Shorter KA, McLellan WA, Pabst A (2001) Bouyant balaenids: the ups and downs of buoyancy in right whales. Proc R Soc Lond B Biol Sci 268:1811-1816

> Nowacek DP, Thorne LH, Johnston DW, Tyack PL (2007) Responses of cetaceans to anthropogenic noise. Mammal Rev 37:81-115

Oberweger K, Goller F (2001) The metabolic cost of birdsong production. J Exp Biol 204:3379-3388

Parks SE, Clark CW (2007) Acoustic communication: social sounds and the potential impacts of noise. In: Kraus SD, Rolland RM (eds) The urban whale: North Atlantic right whales at the crossroads. Harvard University Press, Cambridge, MA, p 310-332

> Parks SE, Tyack PL (2005) Sound production by North Atlantic right whales (Eubalaena glacialis) in surface active groups. J Acoust Soc Am 117:3297-3306

Parks SE, Clark CW, Tyack PL (2007a) Short- and long-term changes in right whale calling behavior: the potential effects of noise on acoustic communication. J Acoust Soc Am 122:3725-3731

> Parks SE, Ketten DR, O'Malley JT, Arruda J (2007b) Anatomical predictions of hearing in the North Atlantic right whale. Anat Rec 290:734-744

Parks SE, Urazghildiiev I, Clark CW (2009) Variability in ambient noise levels and call parameters of North Atlantic right whales in three habitat areas. J Acoust Soc Am 125:1230-1239

Parks SE, Johnson M, Nowacek D, Tyack PL (2011) Individual right whales call louder in increased environmental noise. Biol Lett 7:33-35

> Parks S, Conger L, Cusano D, Van Parijs S (2014) Variation in the acoustic behavior of right whale mother-calf pairs. J Acoust Soc Am 135:2240

Patricelli GL, Blickley JL (2006) Avian communication in urban noise: causes and consequences of vocal adjustment. Auk 123:639-649 
Payne R, Webb D (1971) Orientation by means of long range acoustic signaling in baleen whales. Ann N Y Acad Sci 188:110-141

Pettis HM, Hamilton PK (2015) North Atlantic Right Whale Consortium 2015 Annual Report Card. Report to the North Atlantic Right Whale Consortium. http://www. narwc.org/pdf/2015\%20Report\%20Card.pdf

Richardson WJ, Greene CR, Malme CI, Thomson DH (1995) Marine mammals and noise. Academic Press, San Diego, CA

Ross D (1976) Mechanics of underwater noise. Pergamon Press, New York, NY

Samaran F, Adam O, Guinet C (2010) Detection range modeling of blue whale calls in Southwestern Indian Ocean. Appl Acoust 71:1099-1106

Širović A, Hildebrand JA, Wiggins SM (2007) Blue and fin whale call source levels and propagation range in the Southern Ocean. J Acoust Soc Am 122:1208-1215

Slabbekoorn H, Ripmeester EA (2008) Birdsong and anthropogenic noise: implications and applications for conservation. Mol Ecol 17:72-83

Smith KB (2001) Convergence, stability, and variability of shallow water acoustic predictions using a split-step Fourier parabolic equation model. J Comput Acoust 9: 243-285

Southall BL, Schusterman RJ, Kastak D (2000) Masking in three pinnipeds: underwater, low-frequency critical ratios. J Acoust Soc Am 108:1322-1326

Stafford KM, Mellinger DK, Moore SE, Fox CG (2007) Seasonal variability and detection range modeling of baleen whale calls in the Gulf of Alaska, 1999-2002. J Acoust Soc Am 122:3378-3390

Szabo A, Duffus D (2008) Mother-offspring association in the humpback whale, Megaptera novaeangliae: follow-

Editorial responsibility: Douglas Nowacek,

Beaufort, North Carolina, USA ing behaviour in an aquatic animal. Anim Behav 75: 1085-1092

Taber S, Thomas P (1982) Calf development and mothercalf spatial relationships in southern right whales. Anim Behav 30:1072-1083

Tennessen JB, Parks SE, Langkilde T (2014) Traffic noise causes physiological stress and impairs breeding migration behavior in frogs. Conserv Physiol 2:cou032, doi: 10.1093/conphys/cou032

Todd BJ, Shaw J (2011) Discovering the seafloor of the Bay of Fundy. Fundy Energy Research Network Bi-Annual Newsletter 1. FERN, Wolfville, NS, p 12

Tyack PL, Miller EH (2002) Vocal anatomy, acoustic communication and echolocation. In: Hoelzel AR (ed) Marine mammal biology. Blackwell Science, Oxford, p 142-184

Urick RJ (1983) Principles of underwater sound. Peninsula Publishing, Newport Beach, CA

Wales SC, Heitmeyer RM (2002) An ensemble source spectra model for merchant ship-radiated noise. J Acoust Soc Am 11:1211-1231

Warren PS, Katti M, Ermann M, Brazel A (2006) Urban bioacoustics: it's not just noise. Anim Behav 71:491-502

Weilgart LS (2007) The impacts of anthropogenic ocean noise on cetaceans and implications for management. Can J Zool 85:1091-1116

World Ocean Database (WOD) (2013) National Oceanographic Data Center, National Oceanic and Atmospheric Administration. www.nodc.noaa.gov/OC5/WOD13/ (accessed 7 November 2013)

Yamato M, Ketten DR, Arruda J, Cramer S, Moore K (2012) The auditory anatomy of the minke whale (Balaenoptera acutorostrata): a potential fatty sound reception pathway in a baleen whale. Anat Rec 295:991-998

Submitted: April 21, 2015; Accepted: April 21, 2016 Proofs received from author(s): May 27, 2016 